NASA/TM-2012-217724

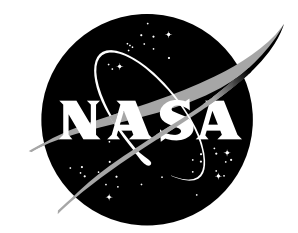

\title{
Highlights From a Mach 4 Experimental Demonstration of Inlet Mode Transition for Turbine-Based Combined Cycle Hypersonic Propulsion
}

Lancert E. Foster and John D. Saunders, Jr.

Glenn Research Center, Cleveland, Ohio

Bobby W. Sanders and Lois J. Weir

TechLand Research, Inc., North Olmsted, Ohio 


\section{NASA STI Program . . . in Profile}

Since its founding, NASA has been dedicated to the advancement of aeronautics and space science. The NASA Scientific and Technical Information (STI) program plays a key part in helping NASA maintain this important role.

The NASA STI Program operates under the auspices of the Agency Chief Information Officer. It collects, organizes, provides for archiving, and disseminates NASA's STI. The NASA STI program provides access to the NASA Aeronautics and Space Database and its public interface, the NASA Technical Reports Server, thus providing one of the largest collections of aeronautical and space science STI in the world. Results are published in both non-NASA channels and by NASA in the NASA STI Report Series, which includes the following report types:

- TECHNICAL PUBLICATION. Reports of completed research or a major significant phase of research that present the results of NASA programs and include extensive data or theoretical analysis. Includes compilations of significant scientific and technical data and information deemed to be of continuing reference value. NASA counterpart of peer-reviewed formal professional papers but has less stringent limitations on manuscript length and extent of graphic presentations.

- TECHNICAL MEMORANDUM. Scientific and technical findings that are preliminary or of specialized interest, e.g., quick release reports, working papers, and bibliographies that contain minimal annotation. Does not contain extensive analysis.

- CONTRACTOR REPORT. Scientific and technical findings by NASA-sponsored contractors and grantees.
- CONFERENCE PUBLICATION. Collected papers from scientific and technical conferences, symposia, seminars, or other meetings sponsored or cosponsored by NASA.

- SPECIAL PUBLICATION. Scientific, technical, or historical information from NASA programs, projects, and missions, often concerned with subjects having substantial public interest.

- TECHNICAL TRANSLATION. Englishlanguage translations of foreign scientific and technical material pertinent to NASA's mission.

Specialized services also include creating custom thesauri, building customized databases, organizing and publishing research results.

For more information about the NASA STI program, see the following:

- Access the NASA STI program home page at http://www.sti.nasa.gov

- E-mail your question to help@sti.nasa.gov

- Fax your question to the NASA STI Information Desk at 443-757-5803

- Phone the NASA STI Information Desk at 443-757-5802

- Write to: STI Information Desk NASA Center for AeroSpace Information 7115 Standard Drive Hanover, MD 21076-1320 
NASA/TM-2012-217724

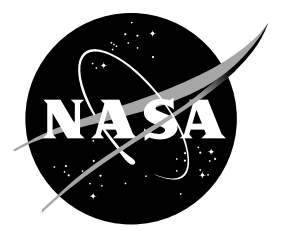

\section{Highlights From a Mach 4 Experimental Demonstration of Inlet Mode Transition for Turbine-Based Combined Cycle Hypersonic Propulsion}

Lancert E. Foster and John D. Saunders, Jr.

Glenn Research Center, Cleveland, Ohio

Bobby W. Sanders and Lois J. Weir

TechLand Research, Inc., North Olmsted, Ohio

Prepared for the

48th Joint Propulsion Conference and Exhibit

cosponsored by AIAA, ASME, SAE, and ASEE

Atlanta, Georgia, July 30 to August 1, 2012

National Aeronautics and

Space Administration

Glenn Research Center

Cleveland, Ohio 44135 


\section{Acknowledgments}

The CCE LIMX development was led by NASA with many partners playing an integral role in the design and development. Project coordination and funding occurred under the aegis of the NASA Fundamental Aeronautics Program under the technical leadership of Mr. Scott Thomas, Dr. Kenneth Suder, and Dr. Jim Pittman. Techland Research, Inc. was the primary contractor for the inlet aerodynamic flowpath design. Alliant Techsystems, Inc. (ATK) had the primary responsibility for the mechanical design and integration of the inlet hardware and also provided a candidate scramjet design which was carried through detailed design. Arctic Slope Regional Corporation (ASRC) also helped with mechanical design and were responsible for much of the design and fabrication of the facility hardware including the strong back. Metalex, Inc. fabricated the majority of the inlet test rig hardware. Williams International is providing the (high Mach) turbine engine via an interagency agreement between NASA and the Air Force Research Lab (AFRL) to develop high speed turbine engines. The integrated turbine engine nozzle was designed and fabricated by Spiritech, Inc. Boeing, Inc. contributed with CFD simulations which helped with test preparations. And finally and most importantly, the authors wish to sincerely thank the NASA GRC in-house facility engineering and technical support team that was led by Christine Pastor-Barsi, G. Scott Williamson, and Daniel Kovach. Their efforts allow quality data to be culled from the most complex inlet model testing in the 10 by 10-Foot Supersonic Wind Tunnel.

Trade names and trademarks are used in this report for identification only. Their usage does not constitute an official endorsement, either expressed or implied, by the National Aeronautics and Space Administration.

This work was sponsored by the Fundamental Aeronautics Program at the NASA Glenn Research Center.

Level of Review: This material has been technically reviewed by technical management.

Available from

NASA Center for Aerospace Information 7115 Standard Drive Hanover, MD 21076-1320
National Technical Information Service 5301 Shawnee Road Alexandria, VA 22312 


\title{
Highlights From a Mach 4 Experimental Demonstration of Inlet Mode Transition for Turbine-Based Combined Cycle Hypersonic Propulsion
}

\author{
Lancert E. Foster and John D. Saunders, Jr. \\ National Aeronautics and Space Administration \\ Glenn Research Center \\ Cleveland, Ohio 44135 \\ Bobby W. Sanders and Lois J. Weir \\ TechLand Research, Inc. \\ North Olmsted, Ohio 44070
}

\begin{abstract}
NASA is focused on technologies for combined cycle, air-breathing propulsion systems to enable reusable launch systems for access to space. Turbine Based Combined Cycle (TBCC) propulsion systems offer specific impulse (Isp) improvements over rocket-based propulsion systems in the subsonic takeoff and return mission segments along with improved safety. Among the most critical TBCC enabling technologies are: 1) mode transition from the low speed propulsion system to the high speed propulsion system, 2) high Mach turbine engine development and 3) innovative turbine based combined cycle integration. To address these challenges, NASA initiated an experimental mode transition task including analytical methods to assess the state-of-the-art of propulsion system performance and design codes. One effort has been the Combined-Cycle Engine Large Scale Inlet Mode Transition Experiment (CCE-LIMX) which is a fully integrated TBCC propulsion system with flowpath sizing consistent with previous NASA and DoD proposed Hypersonic experimental flight test plans. This experiment was tested in the NASA GRC 10 by 10-Foot Supersonic Wind Tunnel (SWT) Facility. The goal of this activity is to address key hypersonic combined-cycle engine issues including: (1) dual integrated inlet operability and performance issues - unstart constraints, distortion constraints, bleed requirements, and controls, (2) mode-transition sequence elements caused by switching between the turbine and the ramjet/scramjet flowpaths (imposed variable geometry requirements), and (3) turbine engine transients (and associated time scales) during transition. Testing of the initial inlet and dynamic characterization phases were completed and smooth mode transition was demonstrated. A database focused on a Mach 4 transition speed with limited offdesign elements was developed and will serve to guide future TBCC system studies and to validate higher level analyses.
\end{abstract}

\section{Nomenclature}

$\begin{array}{ll}\text { AAS } & \text { Air-breathing Access to Space } \\ \text { AoA } & \text { Angle of Attack } \\ \text { AIP } & \text { Aerodynamic Interface Plane } \\ \text { CCE } & \text { Combined Cycle Engine } \\ \text { CCE-LIMX } & \text { Combined Cycle Engine Large Scale Inlet Mode Transition Experiment } \\ \text { DMSJ } & \text { Dual Mode Scramjet } \\ \text { FAP } & \text { Fundamental Aeronautics Program } \\ \text { I }_{\text {sp }} & \text { Specific Impulse } \\ \text { RBCC } & \text { Rocket-Based Combined Cycle }\end{array}$




$\begin{array}{ll}\text { TBCC } & \text { Turbine-Based Combined Cycle } \\ \text { TSTO } & \text { Two-Stage-to-Orbit } \\ \text { VIGV } & \text { Variable Inlet Guide Vanes } \\ 10 \times 10 \text { SWT } & 10 \text { by } 10 \text {-Foot Supersonic Wind Tunnel }\end{array}$

\section{Introduction}

The NASA Fundamental Aeronautics Hypersonics project is focused on technologies for combined cycle, air-breathing propulsions systems to enable Air-breathing Access to Space (AAS). A recent study (Ref. 1), which included an extensive survey of past studies, determined that a turbine-based combined cycle (TBCC) (Ref. 2) was the concept with the greatest promise. A TBCC propulsion system uses a turbine-based engine to accelerate the vehicle from takeoff to the mode transition flight condition (approximately Mach 3 or 4), at which point, the propulsion system performs a "mode transition” from the turbine to a dual mode scramjet (DMSJ) engine, which would then accelerate the vehicle on to hypersonic speed levels. This type of propulsion system has promising potential for Two-Stage-to-Orbit (TSTO) AAS. One benefit of a TBCC system would be a significant improvement in specific impulse $\left(\mathrm{I}_{\mathrm{sp}}\right)$ over rocket-based propulsion systems, during the subsonic takeoff and return phases of a mission, as shown in Figure 1. Turbine-based systems also have the potential for more operational flexibility, allowing for adverse weather launch, cross-range takeoff and landing, and powered landing. There is also a dual-use potential, as turbine engines are serviceable for both low-speed accelerator missions and longrange cruise missions. Another benefit would be the reduced system maintenance.

Mode transition is defined as the smooth change of engine operation from a gas turbine to a dualmode scramjet; this being said, many variations of implementation are possible. These include: mission, vehicle, specific engine cycles and even inlet design. Therefore, this study employed a generic implementation of these variations, such that the resulting database would be usefully representative of TBCC technology. The trade space for vehicle design is complex with unknown tradeoffs between the desired high effective specific impulse versus the increased dry weight fraction due to an air-breathing propulsion system. To maximize benefits, the air-breathing transition Mach numbers were pushed to practical limits: Mach 4 for transition and Mach 7 for staging. Although there are other options, this experimental model was designed with the intent to ground a solid inlet and propulsion system database for future conceptual and preliminary mission studies.

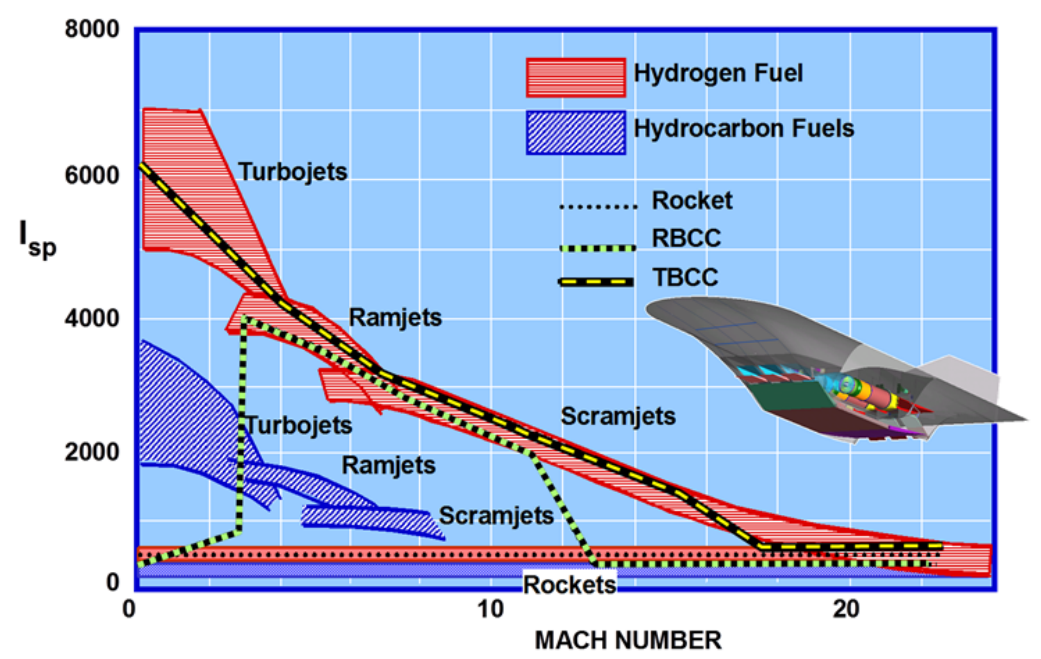

Figure 1.-Comparison of specific impulse for turbine-based and rocket-based propulsion systems. 


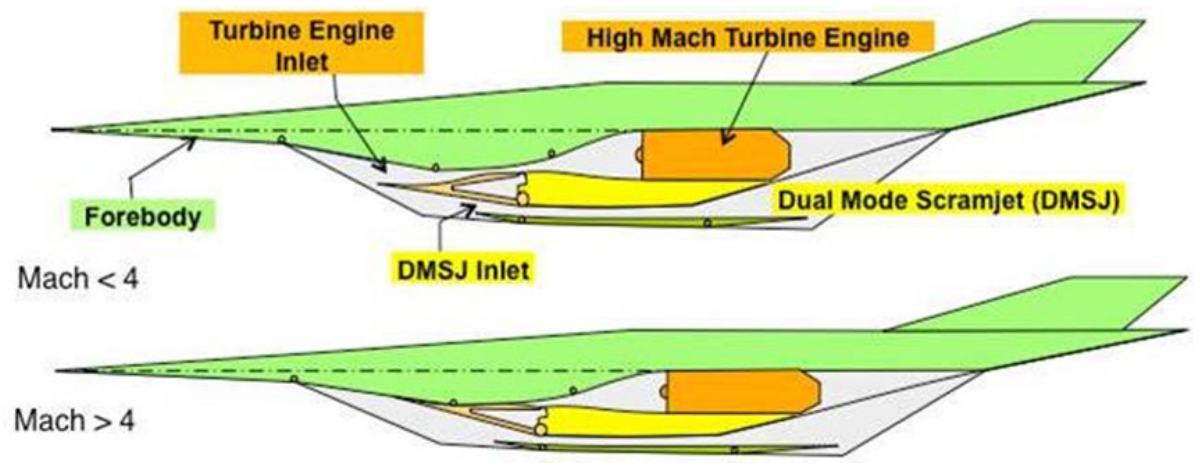

Figure 2.-Operating modes of the TBCC propulsion system.

Based on the Next Generation Launch Technology (NGLT) studies (Ref. 3), the NASA FAP Hypersonics Multidisciplinary Design and Analysis Optimization (MDAO) discipline selected an overunder TBCC system (turbine engine over ram/scramjet) as the reference configuration for a TBCC TSTO vehicle. This over-under TBCC configuration is illustrated in Figure 2. This over-under design, in which the two engines share a common inlet and nozzle, saves weight, compared to a design featuring two separate, non-integrated inlets feeding the separate engine systems. This study investigates a twodimensional inlet concept designed (Ref. 4) with a mode transition Mach number of 4 and a staging Mach number of 7. From takeoff to Mach 4, both inlet ducts would be open with thrust generated primarily by the turbine engine. Once the vehicle accelerated to a condition that would allow ramjet combustion, the high-speed engine would be ignited. Although the high-speed engine would only provide minimal thrust at these lower Mach conditions, combustion might be necessary to fill the nozzle and reduce base drag. Once the vehicle accelerated to Mach 4, the designed inlet mode transition point, the high-speed flowpath would be open to accept appropriate airflow to for a fully operational scramjet engine. The turbine engine would spool down and the "low-speed" flowpath would go from fully open to almost fully closed. From this point, the DMSJ would provide the thrust to accelerate the vehicle to all Mach numbers beyond the mode transition condition. Smooth mode transition is accomplished when flow is diverted from one flowpath to the other, with neither experiencing unstart or buzz (Ref. 5).

A number of enabling technologies require further development for TBCC vehicle systems for hypersonics applications to become a functional reality (Ref. 6). Chief among those is mode transition from the low-speed propulsion system to the high-speed propulsion system. A hypersonic TBCC propulsion system requires a high Mach turbine engine, capable of accelerating a vehicle to near Mach 4, where the scramjet can take over. Conversely, a scramjet must be developed with low ignition speed that can operate at speeds less than Mach 4. Other challenges include transonic aero-propulsion performance as well as the need for innovative three-dimensional flow concepts. In addition, innovative TBCC propulsion/airframe integration concepts will be required to minimize propulsion system dry weight, which stands counter to the projected $\mathrm{I}_{\mathrm{sp}}$ (wet weight) benefit.

This study investigates a two-dimensional inlet concept designed with a mode transition Mach number of 4 and a staging Mach number of 7. The purpose of this study is to understand, demonstrate, and control the mode transition between the low-speed turbine engine and the high-speed DMSJ for a relevant TBCC over-under propulsion configuration. This requires a comprehensive understanding of the characteristics of the dual inlet design and its interactions with the engine and nozzle so that the behavior of the TBCC propulsion system can be modeled and predicted. An integrated performance and operability database must be developed that assesses factors such as: unstart constraints, bleed requirements, and controls characterization. This database will provide realistic distortion characteristics throughout the mode transition Mach number range and assess the impact of this distortion on turbine performance and operability. This will allow validation of computational tools used to predict TBCC propulsion system behavior. Lastly, the hardware from this effort will serve as a testbed for future mode transition controls research and integrated inlet/engine propulsion system studies. 
The planned test series includes four phases which are as follows:

Phase I: Parametric inlet characterization-completed

Phase II: Inlet controls system identification—completed

Phase III: Demonstration of Closed Loop Controls-future work

Phase IV: Fully integrated controlled mode transition with turbine engine—-future work

This paper focuses on the inlet characterization portion of testing (Phase I). The crux of supersonic inlet performance characterization is the effect of design and flow on inlet losses; inlet losses can be measured with total pressure rakes mounted at the engine inlet face. A second important inlet characteristic is “operability”. High Mach number inlets use a mixture of compression, both forward and aft of the cowl lip. Aft compression, also known as internal contraction, is necessary at speeds beyond Mach 2 to reduce losses. However, a major negative side effect of internal compression is the "unstart" phenomenon. With the inlet trimmed to match engine flow, unstart can be triggered by either upstream or downstream perturbations. An inlet's ability to resist these triggering perturbations and maintain started flow is termed operability or stability. The "smooth" mode transition is developed by maintaining performance, avoiding unstart with adequate margins, and providing flow with acceptable levels of distortion.

Downstream perturbations are caused by irregularity in the engine flow which may stem from engine control variations, mechanical degradation or flow instability. Flow instability is perhaps more prevalent in the scramjet duct where shock train and wall separations are present intentionally. The "stability index" is a measure of turbine flowpath stability and is often quantified as the percent change in corrected flow. Scramjet stability has not been extensively examined as of yet. Perturbations upstream of the inlet are typically caused by freestream changes due to atmospheric gusts (thermal upwellings or flow angularity). These disturbances can trigger unstart when they effect a drop in inflow Mach number, an increase in local angle of attack, or an increase in sideslip. In wind tunnel testing, stability for upstream disturbance is usually quantified as the change in Mach or AoA that causes unstart.

Engine compatibility is also an important measure of inlet performance. Clearly, an inlet must match the inflow demands of the engine but distortion is a critical factor in assessing compatibility. The turbine engine community has a well-developed standard for measuring non-uniformities at subsonic and lower supersonic speeds (Ref. 7). Still, engine distortion tolerance is coupled to the individual turbine engine design and limits are usually determined empirically with the engine mounted behind distortion screens (Ref. 8). Turbine distortion metrics are particularly challenging as modern engines rely on dynamic data and may require upwards of 150,000 time slices even to characterize a nominally "steady-state" operating point.

Military Specification (Mil-spec) inlet performance, as measured by total pressure recovery, can be achieved for an inlet carefully designed for single point operation. However for a TBCC system, the inlet must operate over a wide range of flight conditions and distribute the flow with acceptable levels of distortion and unsteadiness to both the turbine engine and DMSJ. Common practice is to use variable geometry and designed bleed configurations to enable a wide range of inlet operability and meet performance requirements, such as maximizing pressure recovery and minimizing flow spillage. However, this added complexity required to achieve high performance and operability results in additional weight, complex vehicle integration, and increased drag. Figure 3 illustrates that the inlet pressure recovery can vary by a factor of $4 \mathrm{X}$ (assuming Mil-spec can be achieved over the Mach flight range) depending on the inlet complexity. Component performance levels (such as total pressure recovery) are used in system trade studies for each vehicle configuration and mission such as air-breathing access to space (AAS). NASA is focusing on the development of validated design and analysis tools as well as parametric databases which are required to perform these system trade studies. Specific questions related to dual inlet technology addressed by CCE-LIMX inlet characterization (Phase I) testing include:

- Is Mil-Spec performance achievable over the wide operating range that is required for TBCC space access?

- What is the trade-off between bleed and inlet performance/operability?

- Can design and analysis tools adequately predict operability limits both with and without bleed? 
- Can these tools predict low-speed/high-speed flowpath interaction effects due to varying inlet backpressures and low-speed/high-speed cowl positions?

- What is the process for safe and optimum mode transition?

In order to maintain propulsion system performance through mode transition, inlet/engine interactions and low-speed/high-speed engine interactions must be controlled to avoid inlet unstarts and engine stalls. All the while, proper airflow quality and distribution must be maintained while the turbine engine is spooled down as the DMSJ takes over. Specific questions with regard to inlet/engine interaction include:

- What impact does inlet distortion have on performance and operability?

- Can design and analysis tools predict distortion into the engine both with and without bleed?

- Can these tools predict the impact of distortion on engine performance and operability?

- What is the trade-off between bleed and inlet exit profile? Are vortex generators required?

Validated design and analysis tools are necessary to enable modeling of TBCC propulsion system characteristics over a wide flight range and during mode transition. Specific questions must be addressed with regard to understanding and demonstrating mode transition such as:

- Can design and analysis tools model components adequately to perform a controlled mode transition?

- Are these predictions of sufficiently high fidelity to guide the testing and avoid inlet unstart and/or engine stall?

- Can these design tools be effectively used to extrapolate the experimental data in order to optimize the propulsion system configuration?

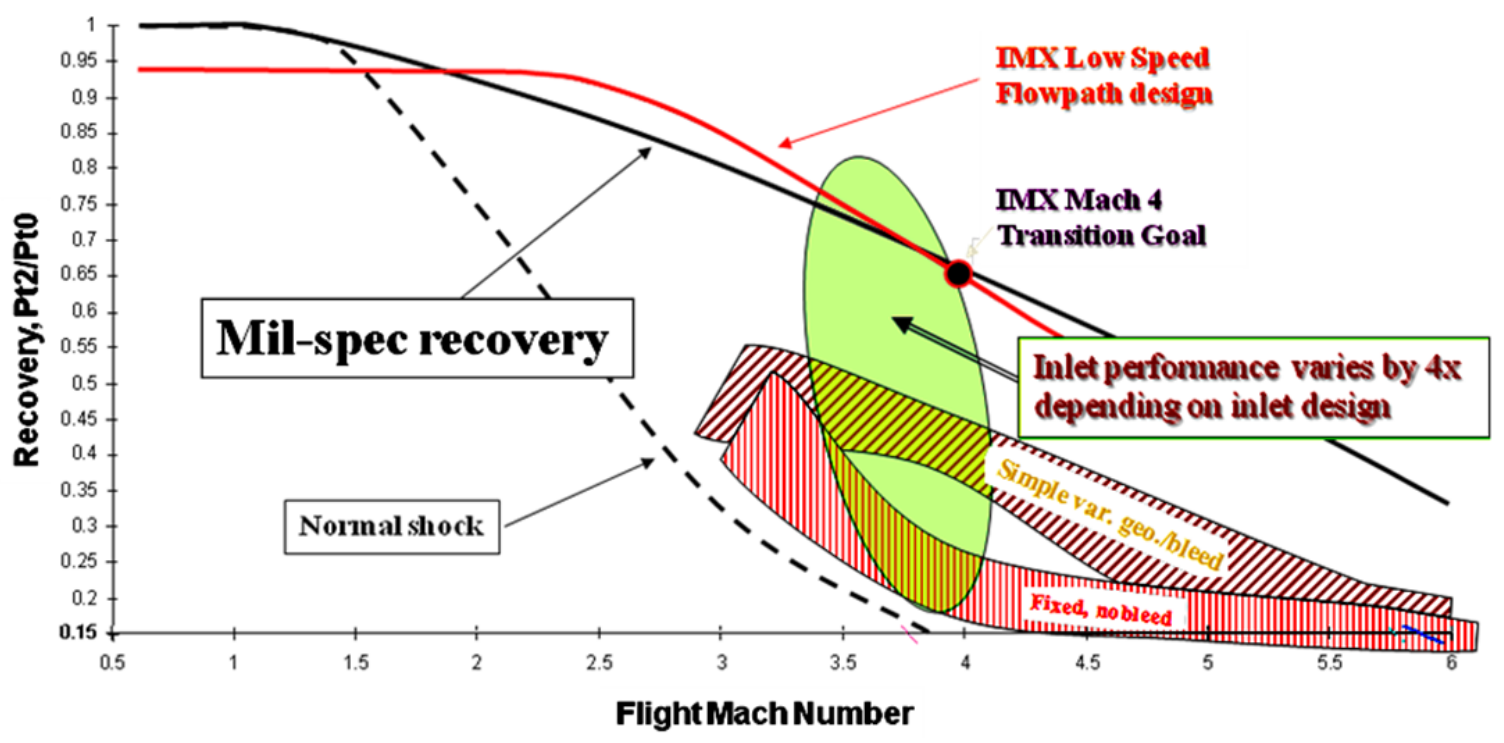

Figure 3.-Potential total pressure recovery for TBCC inlets. 


\section{Experimental Apparatus}

\section{Test Article Description}

Figure 4 shows the CCE-LIMX mounted in the NASA GRC $10 \times 10$ SWT. Figure 5 shows a crosssectional view that illustrates the variable geometry features. The CCE-LIMX is an over-under dual inlet designed for mode transition testing, including controls and integrated inlet and engine testing (Refs. 9 and 10). It features a high-speed flowpath designed to operate at up to Mach 7. The high-speed flowpath has a variable cowl and is mated with an isolator that transitions from rectangular to circular in crosssection. The low-speed flowpath is positioned directly above the high-speed flowpath and has a variable cowl that serves as the outer surface of the high-speed ramp; the low-speed cowl is sometimes referred to as the "splitter", since the lower side serves as the ramp for the high-speed flowpath. The low-speed flowpath also has a variable ramp that allows the throat of the flowpath to be adjusted. Both the cowls and the ramp are controlled by hydraulic actuators. Each flowpath terminates with a constant area coldpipe and is modulated and measured by a variable exit conical plug, which serves as an engine simulator. The low-speed flowpath has 13 bleed regions, with plenums ducted to 15 remotely controlled coldpipe/massflow-plug assemblies. Figure 6 shows the arrangement of these bleed regions throughout the low-speed flowpath. The low-speed flowpath can also be fitted with vortex generators on its ramp, cowl, and sidewalls. Some configurations during Phase I testing did feature vortex generators.

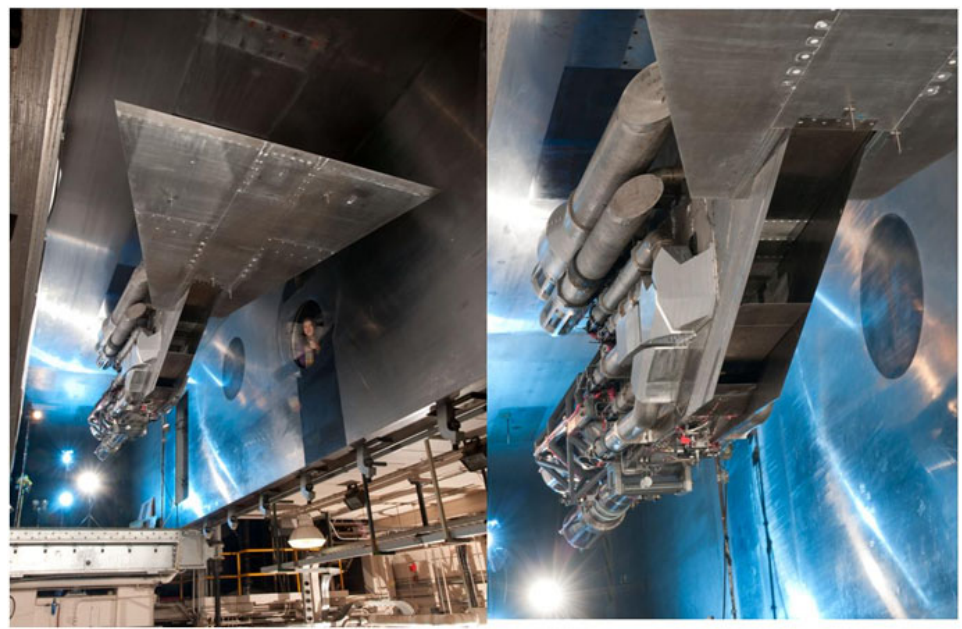

Figure 4.-CCE-LIMX installed in the NASA $10 \times 10$ SWT.

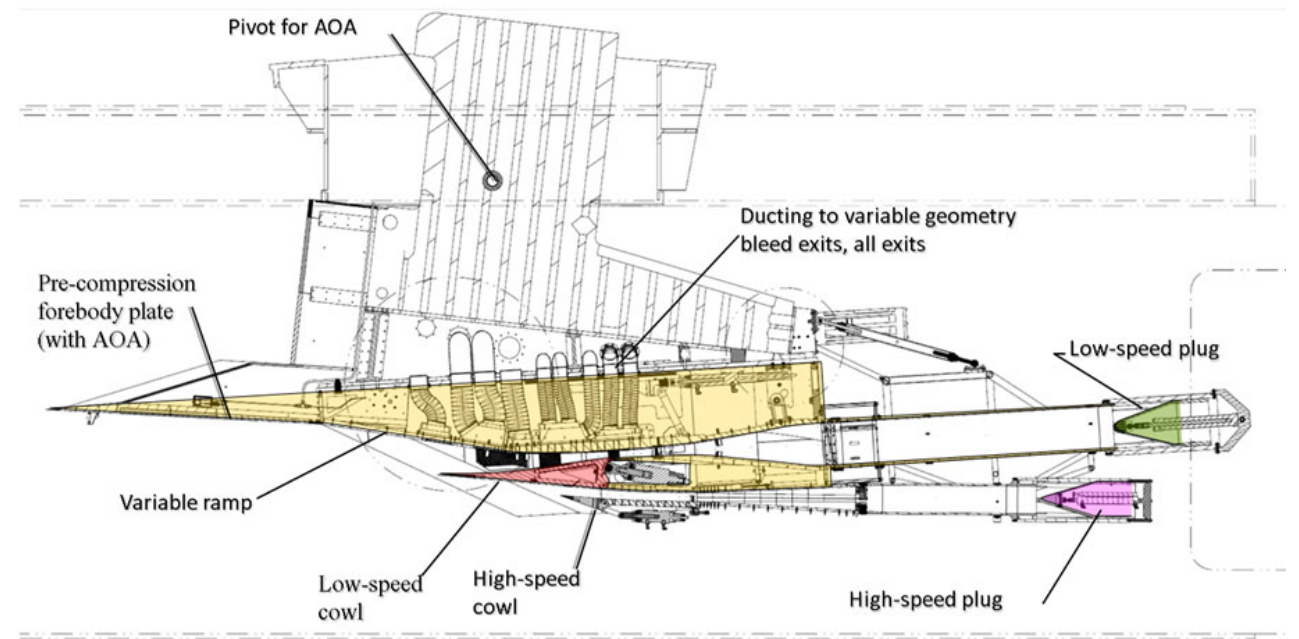

Figure 5.-CCE LIMX installation schematic with highlights of variable geometry features. 


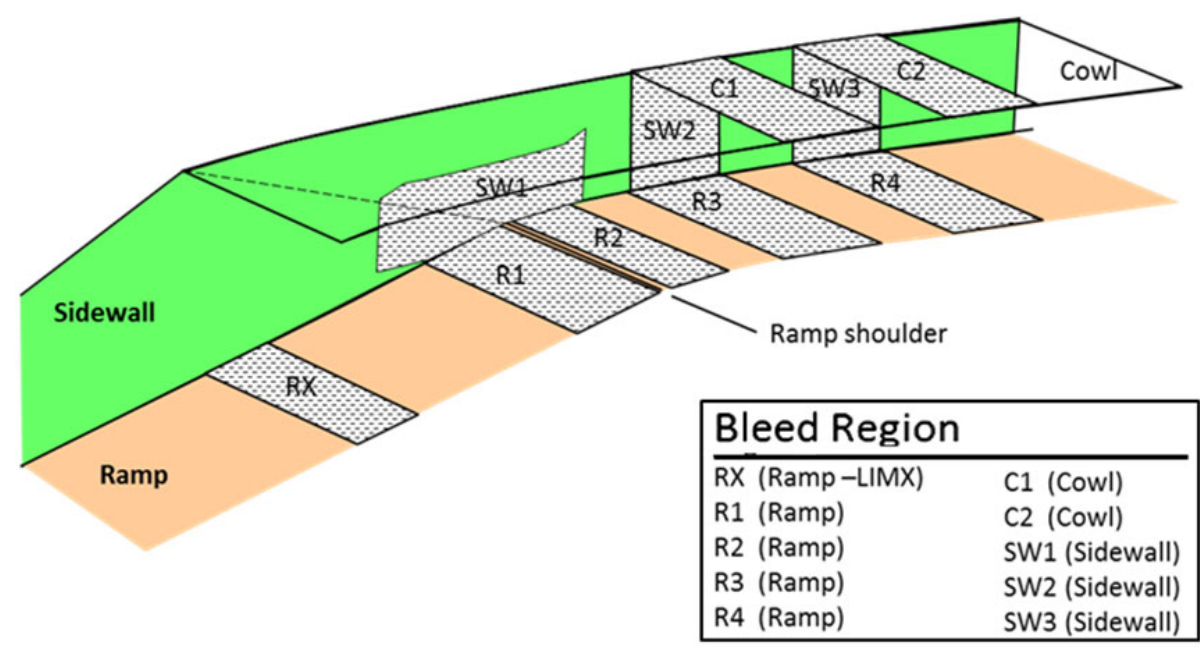

Figure 6.-Bleed configuration for the low-speed flowpath.

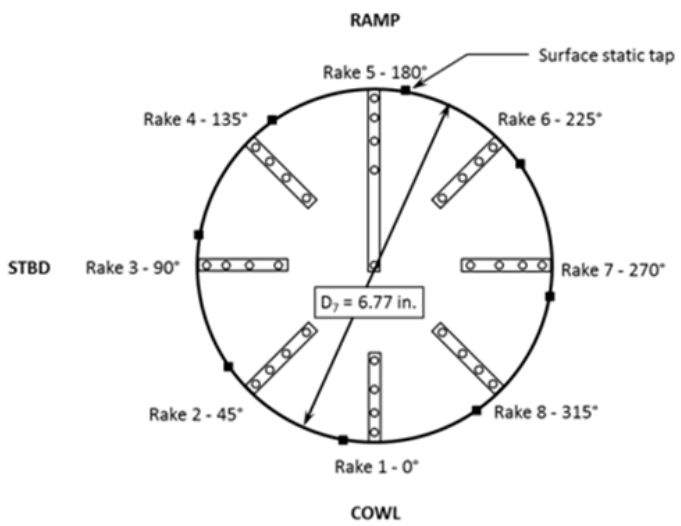

Figure 7.- -High-speed AIP rake array.

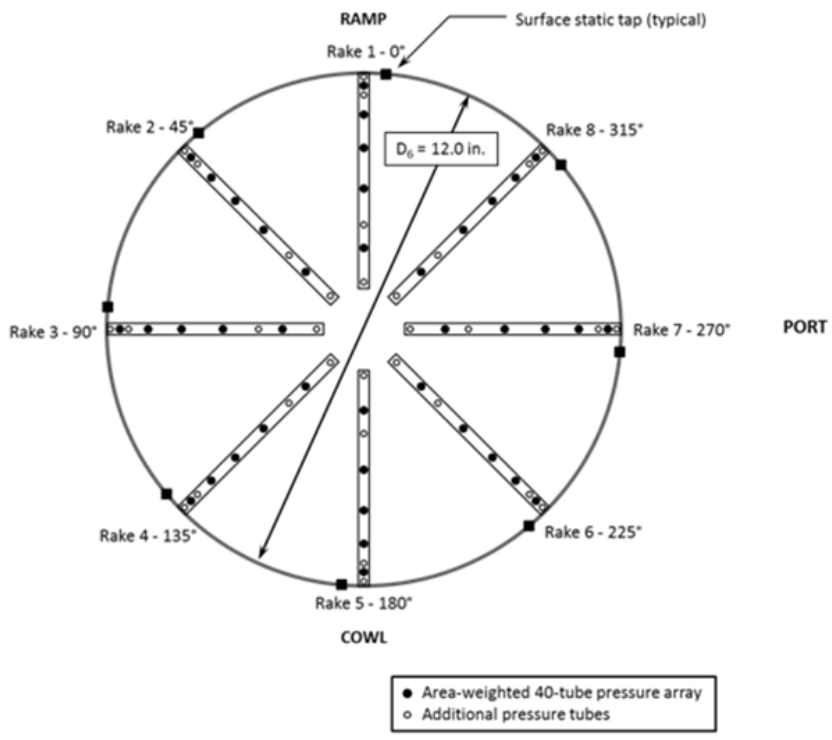

Figure 8.-Low-speed AIP rake array.

\section{Instrumentation}

Both the high-speed and low-speed flowpaths are equipped with longitudinal rows of static pressure taps on both their cowl and ramp flow surfaces. Also, each flowpath is fitted with an aerodynamic interface plane (AIP) rake array as shown in Figures 7 and 8. Each of the area-weighted tubes in the lowspeed array includes a dynamic pressure transducer, in addition to the steady-state tube; this allows determination of industry standard distortion profiles of the flow being fed to the turbine engine. This data is critical for assessing the inlet's compatibility with the CCE Turbine Engine, discussed later in this paper. The CCE Turbine Engine will be mounted to the low-speed duct during Phase IV testing. 


\section{$10 \times 10 \mathrm{SWT}$}

The NASA $10 \times 10$ SWT can operate over a Mach number range of 2 to 3.5 (Ref. 11). Because the tunnel does not operate at Mach 4, this condition must be simulated. This is accomplished by a large trapezoidal plate mounted on the front of the model, clearly visible in Figure 8; this plate is called the “pre-compression ramp”. In an actual Mach 4 flow, there would be Mach 3.533 flow over the precompression ramp due to the oblique shock caused by the $6.5^{\circ}$ ramp angle, as shown in Figure 9 . The CCE-LIMX is mounted to the facility strut and the angle of attack (AoA) can be varied from $-15^{\circ}$ to $+5^{\circ}$. With the tunnel operating at Mach 3.5 and the CCE-LIMX at an approximate AoA of $-6.5^{\circ}$, as shown in Figure 10, a very small expansion angle on the pre-compression ramp gives us Mach 3.533 flow. In regard to the inlet, the only aerodynamic difference between actual Mach 4 freestream flow and simulated Mach 4 is the total pressure recovery across the oblique shock. The variation in total pressure loss is corrected for in the recorded data.

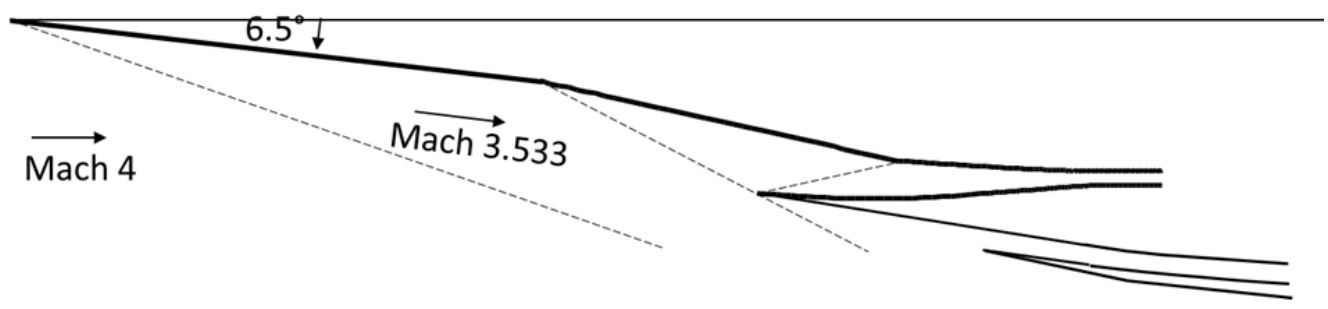

Figure 9.--Inlet and attitude at Mach 4 flight condition.
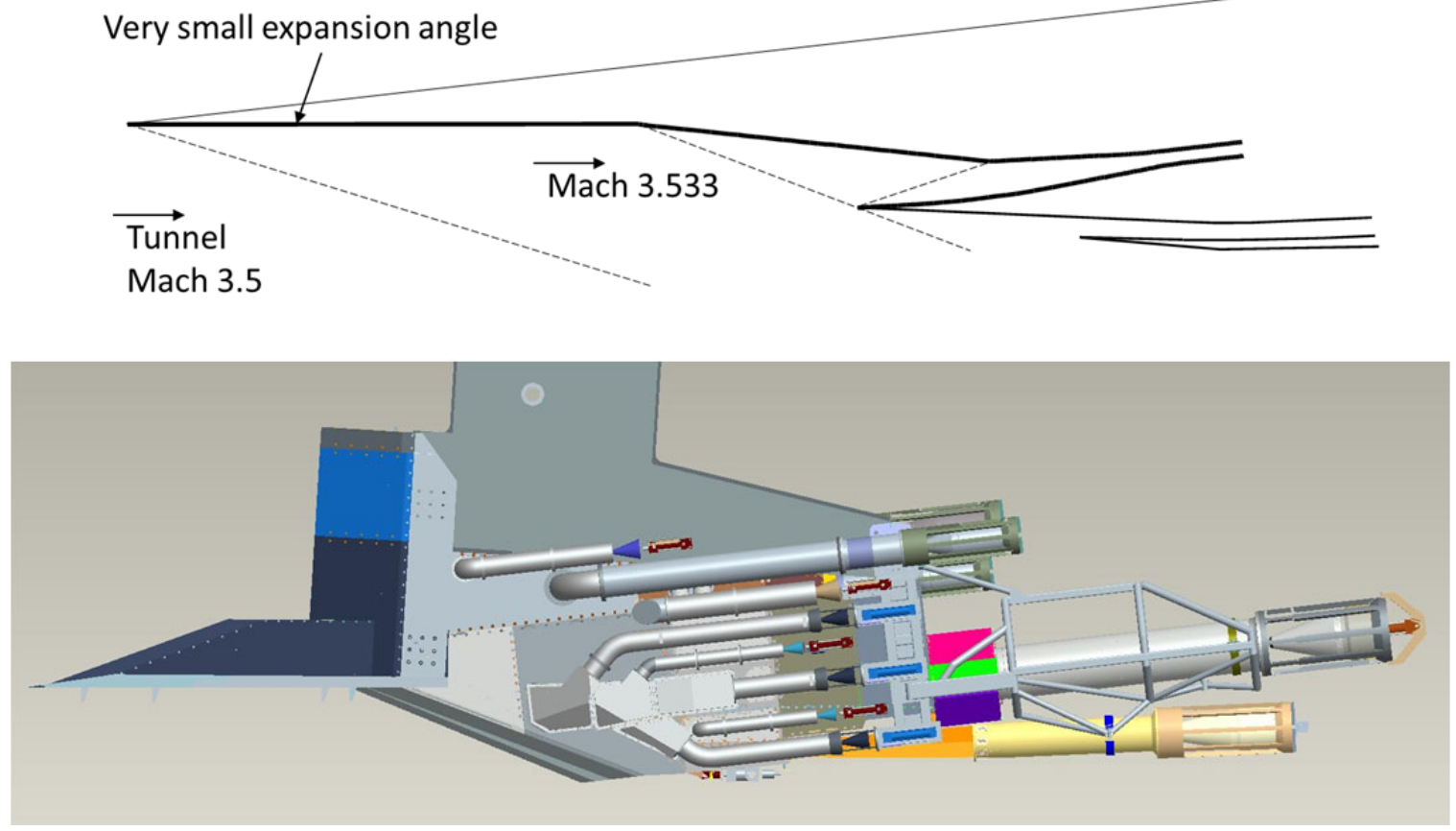

Figure 10.-CCE-LIMX at simulated Mach 4 tunnel condition. 


\section{Mach 3 Capable Turbine Development}

Phase IV of CCE LIMX testing includes removing the coldpipe and mass-flow plug assembly from the low-speed flowpath and replacing it with an actual Mach 3 capable turbine engine. Therefore, Williams International has developed and built an engine for this purpose. The CCE Turbine Engine is a modified version of Williams' WJ38 Turbine Engine with some adaptations for Mach 3 operation. Figure 11 shows a photo of the engine and the integrated nozzle assembly. The production WJ38 is not suited to accommodate the increased distortion levels and temperature; the CCE engine must tolerate a $600^{\circ} \mathrm{F}$ max inlet temperature. Thus, a distortion- and temperature-tolerant fan, incorporating forwardswept blades, was added along with variable inlet guide vanes (VIGV). To accommodate the increased temperature, material changes were made in some compressor and lubrication system components. Flame spray abradable was added to some compressor surfaces and Thermal Barrier Coating (TBC) was added to the combustor. Lastly, an afterburner and Single Expansion Ramp Nozzle (SERN) were added to the engine, allowing for improved supersonic operation. Because the CCE engine was designed for ground testing in the NASA GRC $10 \times 10$ SWT with no particular performance specifications in mind, it was not weight-optimized as a comparable flight engine would be. The engine is currently available and has undergone sea level static (SLS) checkout tests. A final series of checkout/acceptance testing was conducted with an afterburner and integrated nozzle installed in May 2011. Following post-test inspections, the engine was delivered to NASA GRC on August 2, 2011.
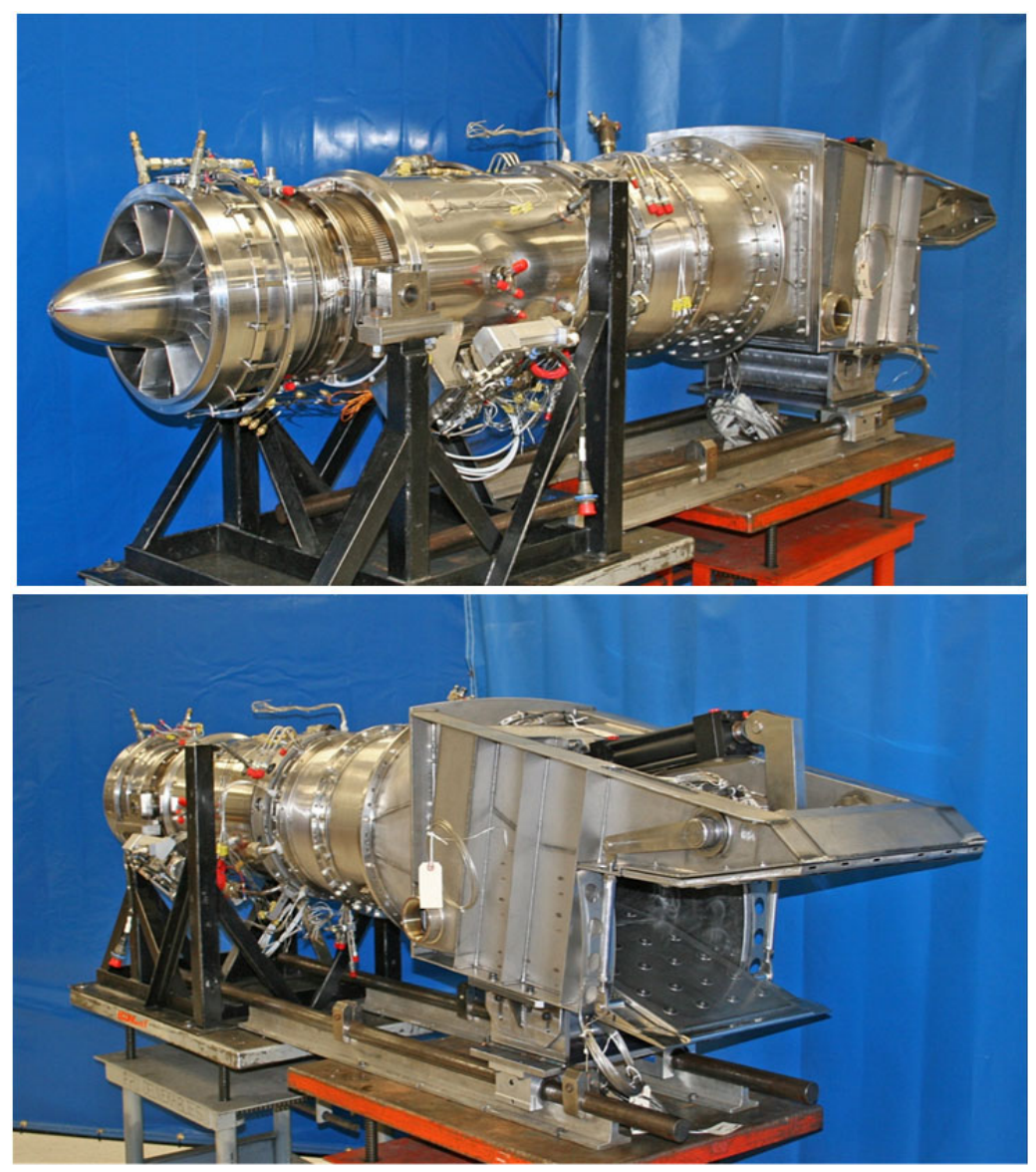

Figure 11.-Williams International High Mach WJ38 turbine engine and integrated nozzle assembly. 


\section{Results and Discussion}

The inlet performance and operability tests (Phase I) encompassed 30 run nights and $145 \mathrm{hr}$ on condition. Comprehensive data sets were obtained at Mach 4 and 3, while limited data sets were obtained at Mach 3.5, 2.5, and 2. Note that different configurations in terms of inlet features such as ramp/cowl settings, low-speed cowl leading edge, boundary layer bleed patterns, and vortex generator design were studied. The system identification/dynamics tests (Phase II) encompassed 17 run nights and $90 \mathrm{hr}$ on condition. A total of 651 dynamic experiments were conducted; 495 at Mach 4 and 156 at Mach 3.

Due to security restrictions on the data, quantitative details cannot be presented in this open paper. Full detailed test results will be presented later; however, Mach 4 results are currently available (Ref. 5). Figure 12 shows a qualitative representation of the mode transition data acquired during testing. This mode transition map for the low-speed flowpath is composed of curves of total pressure recovery versus duct exit flow ratio. The curves are termed "inlet performance canes". Each successive inlet cane (as the cowl lip was moved toward the closed position) moved to a lower mass-flow ratio with a reduced recovery at the data point that was recorded just prior to inlet unstart (minimum stable). The ultimate objective is to achieve full system mode transition without incurring inlet unstart, inlet buzz or engine stall. Initial test results indicate that successful and smooth inlet mode transition was demonstrated with a split-flow TBCC inlet system.

The results schematically represented in Figure 12 for the low-speed flowpath, along with the highspeed flowpath results, are being compared to pre-test computational solutions and to the small scale inlet mode transition experiment (IMX) results previously obtained in the NASA GRC $1 \times 1$ SWT (Ref. 12). The unstart and distortion limits are depicted as shaded regions in Figure 12.

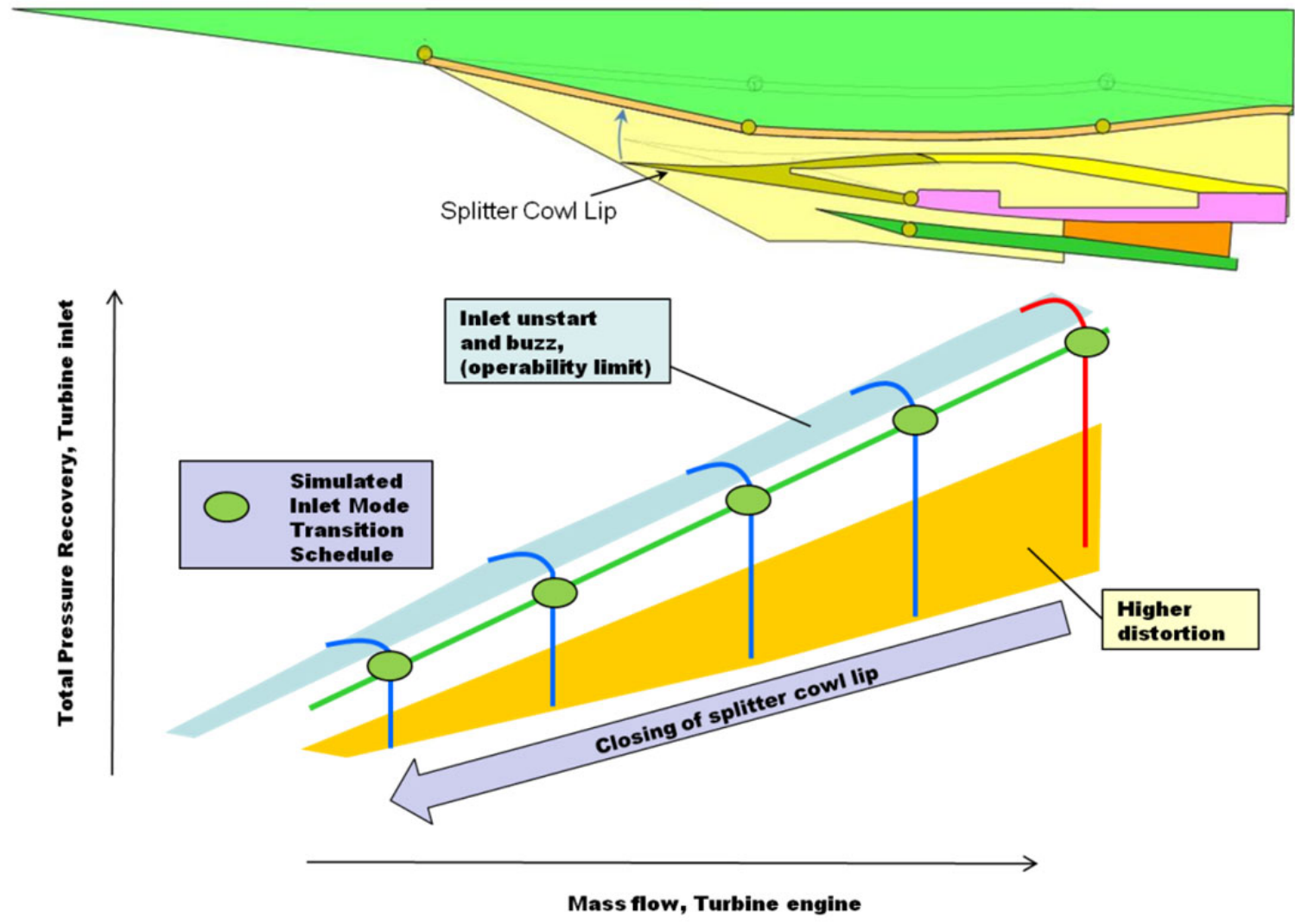

Figure 12.-Schematic plot of mode transition sequence representative of low-speed inlet test data. 
Internal contraction ratio limits were found for both flowpaths with limited variation of bleed, Mach number, and ramp geometry. With this information, two mode transition tracks were determined for the high-speed flowpath: an aggressive one, with better thrust performance, and a conservative one, with more stability. Delta Mach and AoA limits were also found. Parametric testing provided a design database that includes: bleed versus recovery trades, bleed versus engine inlet distortion trades, and unstart and distortion limits.

Dynamic data were obtained with the low-speed AIP rake at conditions appropriate for operation of the CCE Turbine Engine. This was done in a manner consistent with turbine industry standards for assessing engine inflow quality, which allows the calculation of distortion indices. Distortion profiles will be incorporated into analytical tools to predict engine performance and operability constraints, in preparation for fully integrated testing.

For a scramjet engine, a distortion profile can be used to calculate the mass flow distribution. These profiles might enable scramjet designs that include differential fuel distribution to approximate constant fuel/air ratio combustion. To date, aspects of even basic scramjet control continue to be researched (Ref. 13). Nonetheless, dynamic data from the CCE-LIMX high-speed flowpath will prove useful as the isolator duct is coupled to a relevant TBCC dual inlet.

Further development of the TBCC propulsion concept is needed to address the transient nature of mode transition. Certain aspects of the mode transition remain unknown, as they are dependent on the selection of a specific mission and vehicle. Ideally, acceleration would be maintained or even enhanced during mode transition and in trimmed flight, AoA would probably vary as well. If net thrust production were to lag during the transition, vehicle deceleration could result. To simplify these unknowns in the current testing, Mach and AoA were generally kept constant during mode transition. Development of this database will help to remove some of these unknowns. The primary focus was on a transition Mach number of 4 to match the inlet design point. However, a secondary constant Mach transition was also investigated at Mach 3. This alternate Mach condition matched the upper performance limit of the CCE turbine engine built for this project.

Limited data were also gathered at M3.5, 2.5, and 2.0. These intermediate points provide skeletal TBCC performance information across the operating range: from starting Mach numbers (around Mach 2) through the main turbine thrust production (Mach 2.5) and on to the mid-point of mode transition speed (Mach 3.5).

Eventually, variable Mach mode transition must be investigated as well. A representative accelerating mode transition was conducted, although a more comprehensive study of Mach and AoA variations will be called for in the future. Data from this study reveals specific details of Mach and AoA variation, which enables their incorporation into the mode transition modelling of further mission studies.

Dynamic data were obtained to capture the details of transients present during mode transition. These data were used validate design and analysis approaches (Refs. 14 and 15) and are available to prepare control laws for close-looped mode transition.

With the resulting database, propulsion system design approaches can be validated. The inlet design approach was outlined in the work of Sanders and Weir (Ref. 4). In the completed test to date, the inlet design intent can be compared to the test results. Where the inlet deviates from expected behavior, the large database will be scrutinized and modifications or refinements to the design methods will be reported and incorporated into the next generation of designs.

Alternate model configurations were tested to widen the applicability of the database and provide some means to improve performance. These variations included: alternate cowl lips, vortex generators, and bleed variations for the turbine flowpath. Depending on baseline configuration results, testing of alternate configurations could be extensive or very limited. Six run nights, or about 5 percent of the testing, were devoted to this investigation. The effect of bleed complexity was also investigated; by closing various bleed exits, the effect of reduced bleed complexity on low-speed flowpath performance could be quantified. 
Using selected configurations, the inlet was characterized for performance and operability. A large amount of test time was devoted to testing at Mach 4 conditions. A lesser but still significant amount of the test matrix was used to look at selected geometry at the turbine engine compatible speed of Mach 3. Where performance expectations were met, mode transition was investigated and documented at each of these two "design" Mach numbers.

The validation of advanced CFD-based analytical tools is of critical importance. Though RANS solvers have become production tools for many flows, prediction of supersonic inlet flow remains challenging. In particular, the interplay of the normal and oblique shock with the bleed zones in the turbine flowpath, the prediction of an isolator shock-train in the scramjet flowpath and the characterization of the distortion field at the inlet duct exits are goals that this inlet database will help address. Beyond RANS solvers, future algorithms are under development that may be confirmed with the inlet database.

A significant amount of pre-test CFD analysis was completed in preparation for the objective of CFD tool validation (Refs. 16 to 18). Most of this effort was focused on the transition design point of Mach 4. On-going CFD will continue this effort and investigate the depth of the database at off-design Mach numbers and alternate configurations.

\section{Conclusion}

One of the missions of the NASA Aeronautics Research Directorate (ARMD) FAP Hypersonics project is to develop propulsion technology for AAS. The focus of this effort is in developing an inlet database for the TBCC TSTO propulsion system. There are many technical challenges involved with the development of a TBCC propulsion system and these were discussed in this paper. The CCE-LIMX article tested to date included mass-flow plug and cold pipe assemblies in both the low-speed and highspeed flowpaths. For Phase IV, a high Mach capable turbine engine and single expansion ramp nozzle (SERN) would be incorporated into the low-speed flowpath. This engine and nozzle have also been developed as a part of the TBCC discipline.

Overall this test activity has provided a rather comprehensive database on this TBCC design. Specific results were:

1. Phases I and II of TBCC testing (Parametric inlet characterization tests and Inlet system identification tests) were successfully completed.

2. A database was compiled for a dual inlet for TBCC mode transition which includes performance and operability information. Total pressure recovery, unstart limits, and distortion levels are documented for both flowpaths. Limited configuration effects from bleed, cowl lip, vortex generator, and contraction ratio were investigated.

3. Smooth mode transition was demonstrated in the inlet at a variety of Mach numbers.

4. Data was taken at conditions corresponding to the requirements of the CCE Turbine Engine.

5. The data collected enabled Phase III controls efforts: 1) Identify the frequency range where a closedloop control system is needed to enhance the inlet stability margin; and 2) Determine control design linear models (CDMs) for closed loop control of the CCE-LIMX to simulate a hypersonic vehicle propulsion system mode transition.

Future tests are now possible which will serve to demonstrate controlled mode transition, a requirement for an advanced air-breathing propulsion system that enables hypersonic flight. Beyond the first two phases of this current study, the CCE LIMX testbed will be available to address future national needs in combined cycle propulsion. 


\section{References}

1. Bartolotta, P., Wilhite, A.W., Schaffer, M., Voland, R.T., and Huebner, L., "Horizontal Launch: A Versatile Concept for Assured Space Access,” NASA/SP-2011-2151994; DFRC-E-DAA-TN4418, December 2011.

2. Science Applications International Corporation, "Integrated Concept Model 2 (ICM-2): A twostage-to-orbit turbine based combined cycle concept,” ASAP Team Final Report, 21 February 2003.

3. Bilardo, V.J., Curran, F.M., Hunt, J.L., Lovell, N.T., Wilhite, A.W., and McKinney, L.E., "The Benefits of Hypersonic Airbreathing Launch Systems for Access to Space,” AIAA 2003-5265, 39 ${ }^{\text {th }}$ AIAA/ASME/SAE/ASEE Joint Propulsion Conference, Huntsville, AL, 20-23 July 2003.

4. Sanders, B.W., and Weir, L.J.: "Aerodynamic Design of a Dual-Flow Mach 7 Hypersonic Inlet System for a Turbine-Based Combined-Cycle Hypersonic Propulsion System,” NASA-CR-2008215214, June 2008.

5. Sanders, B.W., Weir, L.J., Saunders, J.D., and Foster, L.E., "Mach 4 Experimental Demonstration of Inlet Mode Transition Technology for a Turbine-Based Combined Cycle Hypersonic Propulsion System,” NASA/TM-2012-217647; September 2012.

6. NIA Report, Boeing Contractor Report, Contract No. 2900-HY04, February 18, 2005.

7. SAI S-16 Committee, “Aerospace Recommended Practice: Gas Turbine Engine Inlet Flow Distortion Guidelines,” Society of Automotive Engineers America Recommended Practice, ARP 1420B, March 2002.

8. Rock, K.E., Nugent, M.R., Orme, J.S., and Calleja, J.F., "Propulsion Subsystem Control Law Development for the Hyper-X Mach 7 Flight Test,” Limited by Export Administration Regulations (EAR), JANNAF $24^{\text {th }}$ Airbreathing Propulsion Subcommittee and $36^{\text {th }}$ Combustion Subcommittee Joint Meeting/Volume 2; 205-226; CPIA-Publ-Vol-2, October 1999.

9. Saunders, J.D., Slater, J.W., Dippold, V.F., Weir, L.J., and Sanders, B.W., "Inlet Research Status for a Large-Scale Turbine-Based Combined Cycle Engine Testbed,” JANNAF, La Jolla, CA, December 7-11, 2009.

10. Saunders, J.D., Stueber, T.J., Thomas, S.R., Suder, K.L., Weir, L.J., and Sanders, B.J., “Testing of the NASA Hypersonics Project Combined Cycle Engine Large Scale Inlet Mode Transition Experiment (CCE LIMX),” NASA/TM-2012-217217, 2012.

11. Soeder, R.H., Roeder, J.W., Linne, A.A., and Panek, J.W., "User Manual for NASA Glenn 10-by 10-Foot Supersonic Wind Tunnel,” NASA/TM-2004-212697, May 2004.

12. Saunders, J.D., Slater, J.W., Dippold, V.F., Lee, J., Sanders, B.W., and Weir, L.J., "Inlet Mode Transition Screening Test for a Turbine-Based Combined-Cycle Propulsion System,” JANNAF, Boston, MA, May 13, 2008.

13. Prahst, P.S., and Suder, K.L., “Results of the High Mach Fan Rig Experiment,” NASA 2012 Fundamental Aeronautics Program Annual Meeting, Cleveland, OH, March 2012.

14. Csank, J., and Stueber, T.J., "A Turbine Based Combined Cycle Engine Inlet Model and Mode Transition Based on HiTECC Tool,” JPC, Atlanta, GA, July 30-August 2, 2012.

15. Le, D.K., Vrnak, D.R., Slater, J.W., and Hessel, O.E., “A Simulation Scheme for Turbine-based Combined Cycles Inlet Mode-Transition Control,” JPC, Atlanta, GA, July 30-August 2, 2012.

16. Slater, J.W., and Saunders, J.D., "CFD Simulation of Hypersonic TBCC Inlet Mode Transition," AIAA-2009-7349, 16th AIAA/DLR/DGLR International Space Planes and Hypersonic Systems and Technologies Conference, October 2009.

17. Dippold, V.F., "Computational Analyses of the LIMX TBCC Inlet High-Speed Flowpath,” $58^{\text {th }}$ JANNAF Propulsion Meeting, April 2011.

18. McDaniel, J., “An Overview of the National Center for Hypersonic Combined-Cycle Propulsion,” NASA 2012 Fundamental Aeronautics Program Annual Meeting, Cleveland, OH, March 2012. 


\begin{tabular}{|c|c|c|}
\hline \multicolumn{2}{|c|}{ REPORT DOCUMENTATION PAGE } & $\begin{array}{l}\text { Form Approved } \\
\text { OMB No. 0704-0188 }\end{array}$ \\
\hline \multicolumn{3}{|c|}{$\begin{array}{l}\text { The public reporting burden for this collection of information is estimated to average } 1 \text { hour per response, including the time for reviewing instructions, searching existing data sources, gathering and maintaining the } \\
\text { data needed, and completing and reviewing the collection of information. Send comments regarding this burden estimate or any other aspect of this collection of information, including suggestions for reducing this } \\
\text { burden, to Department of Defense, Washington Headquarters Services, Directorate for Information Operations and Reports (0704-0188), 1215 Jefferson Davis Highway, Suite } 1204 \text {, Arlington, VA } 22222-2302 \text {. } \\
\text { Respondents should be aware that notwithstanding any other provision of law, no person shall be subject to any penalty for failing to comply with a collection of information if it does not display a currently valid OMB } \\
\text { control number. } \\
\text { PLEASE DO NOT RETURN YOUR FORM TO THE ABOVE ADDRESS. }\end{array}$} \\
\hline $\begin{array}{l}\text { 1. REPORT DATE (DD-MM-YYYY) } \\
01-12-2012\end{array}$ & $\begin{array}{l}\text { 2. REPORT TYPE } \\
\text { Technical Memorandum }\end{array}$ & 3. DATES COVERED (From - To) \\
\hline \multirow{3}{*}{\multicolumn{2}{|c|}{$\begin{array}{l}\text { 4. TITLE AND SUBTITLE } \\
\text { Highlights From a Mach } 4 \text { Experimental Demonstration of Inlet Mode Transition for Turbine- } \\
\text { Based Combined Cycle Hypersonic Propulsion }\end{array}$}} & 5a. CONTRACT NUMBER \\
\hline & & 5b. GRANT NUMBER \\
\hline & & 5c. PROGRAM ELEMENT NUMBER \\
\hline \multirow{3}{*}{\multicolumn{2}{|c|}{$\begin{array}{l}\text { 6. AUTHOR(S) } \\
\text { Foster, Lancert, E.; Saunders, John, D., Jr.; Sanders, Bobby, W.; Weir, Lois, J. }\end{array}$}} & 5d. PROJECT NUMBER \\
\hline & & 5e. TASK NUMBER \\
\hline & & $\begin{array}{l}\text { 5f. WORK UNIT NUMBER } \\
\text { WBS 599489.02.07.03.07.11.01 }\end{array}$ \\
\hline \multicolumn{2}{|c|}{$\begin{array}{l}\text { 7. PERFORMING ORGANIZATION NAME(S) AND ADDRESS(ES) } \\
\text { National Aeronautics and Space Administration } \\
\text { John H. Glenn Research Center at Lewis Field } \\
\text { Cleveland, Ohio 44135-3191 }\end{array}$} & $\begin{array}{l}\text { 8. PERFORMING ORGANIZATION } \\
\text { REPORT NUMBER } \\
\text { E-18435 }\end{array}$ \\
\hline \multirow{2}{*}{\multicolumn{2}{|c|}{$\begin{array}{l}\text { 9. SPONSORING/MONITORING AGENCY NAME(S) AND ADDRESS(ES) } \\
\text { National Aeronautics and Space Administration } \\
\text { Washington, DC 20546-0001 }\end{array}$}} & $\begin{array}{l}\text { 10. SPONSORING/MONITOR'S } \\
\text { ACRONYM(S) } \\
\text { NASA }\end{array}$ \\
\hline & & $\begin{array}{l}\text { 11. SPONSORING/MONITORING } \\
\text { REPORT NUMBER } \\
\text { NASA/TM-2012-217724 }\end{array}$ \\
\hline
\end{tabular}

\section{DISTRIBUTIONIAVAILABILITY STATEMENT}

Unclassified-Unlimited

Subject Category: 07

Available electronically at http://www.sti.nasa.gov

This publication is available from the NASA Center for AeroSpace Information, 443-757-5802

\section{SUPPLEMENTARY NOTES}

\section{ABSTRACT}

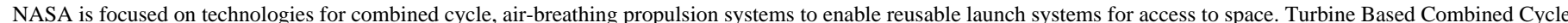
(TBCC) propulsion systems offer specific impulse (Isp) improvements over rocket-based propulsion systems in the subsonic takeoff and return mission segments along with

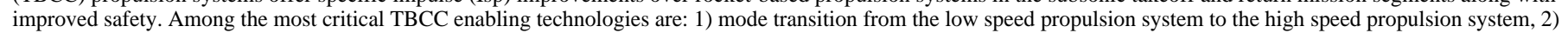
high Mach turbine engine development and 3) innovative turbine based combined cycle integration. To address these challenges, NASA initiated an experimental mode

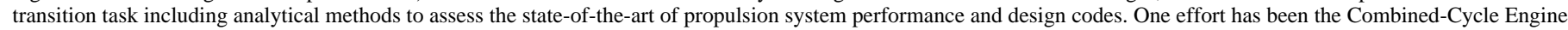
Large Scale Inlet Mode Transition Experiment (CCE-LIMX) which is a fully integrated TBCC propulsion system with flowpath sizing consistent with previous NASA and DoD proposed Hypersonic experimental flight test plans. This experiment was tested in the NASA GRC 10 by 10-Foot Supersonic Wind Tunnel (SWT) Facility. The goal of this activity is to address key hypersonic combined-cycle engine issues including: (1) dual integrated inlet operability and performance issues-unstart constraints, distortion constraints, bleed requirements, and controls, (2) mode-transition sequence elements caused by switching between the turbine and the ramjet/scramjet flowpaths (imposed

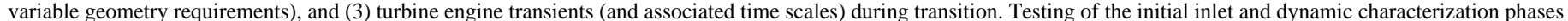
were completed and smooth mode transition was demonstrated. A database focused on a Mach 4 transition speed with limited off-design elements was developed and will serve to guide future TBCC system studies and to validate higher level analyses.

15. SUBJECT TERMS

Hypersonic inlets; Supersonic inlets; Inlet design; Inlet test

\begin{tabular}{|c|c|c|c|c|c|}
\hline \multicolumn{3}{|c|}{ 16. SECURITY CLASSIFICATION OF: } & \multirow{2}{*}{$\begin{array}{l}\text { 17. LIMITATION OF } \\
\text { ABSTRACT } \\
\text { UU }\end{array}$} & \multirow{2}{*}{$\begin{array}{l}\text { 18. NUMBER } \\
\text { OF } \\
\text { PAGES } \\
20\end{array}$} & \multirow{2}{*}{$\begin{array}{l}\text { 19a. NAME OF RESPONSIBLE PERSON } \\
\text { STI Help Desk (email:help@sti.nasa.gov) } \\
\text { 19b. TELEPHONE NUMBER (include area code) } \\
\text { 443-757-5802 }\end{array}$} \\
\hline $\begin{array}{l}\text { a. REPORT } \\
U\end{array}$ & $\begin{array}{l}\text { b. ABSTRACT } \\
U\end{array}$ & $\begin{array}{l}\text { c. THIS } \\
\text { PAGE } \\
\text { U }\end{array}$ & & & \\
\hline
\end{tabular}



